\title{
Impact of acetylsalicylic acid in patients undergoing cerebral aneurysm surgery - should the neurosurgeon really worry about it?
}

\author{
Ali Rashidi ${ }^{1} \cdot$ Nadine Lilla $^{1} \cdot$ Martin Skalej $^{2} \cdot$ I. Erol Sandalcioglu ${ }^{1} \cdot$ Michael Luchtmann $^{1}$ (D) \\ Received: 8 September 2020 / Revised: 16 December 2020 / Accepted: 8 January 2021 / Published online: 25 January 2021 \\ (C) The Author(s) 2021
}

\begin{abstract}
There has been an increase in the use of acetylsalicylic acid (ASA, Aspirin ${ }^{\circledR}$ ) among patients with stroke and heart disease as well as in aging populations as a means of primary prevention. The potentially life-threatening consequences of a postoperative hemorrhagic complication after neurosurgical operative procedures are well known. In the present study, we evaluate the risk of continued ASA use as it relates to postoperative hemorrhage and cardiopulmonary complications in patients undergoing cerebral aneurysm surgery. We retrospectively analyzed 200 consecutive clipping procedures performed between 2008 and 2018. Two different statistical models were applied. The first model consisted of two groups: (1) group with No ASA impact - patients who either did not use ASA at all as well as those who had stopped their use of the ASA medication in time $(>=7$ days prior to operation); (2) group with ASA impact - all patients whose ASA use was not stopped in time. The second model consisted of three groups: (1) No ASA use; (2) Stopped ASA use (> = 7 days prior to operation); (3) Continued ASA use (did not stop or did not stop in time, $<7$ days prior to operation). Data collection included demographic information, surgical parameters, aneurysm characteristics, and all hemorrhagic/thromboembolic complications. A postoperative hemorrhage was defined as relevant if a consecutive operation for hematoma removal was necessary. An ASA effect has been assumed in 32 out of 200 performed operations. A postoperative hemorrhage occurred in one out these 32 patients (3.1\%). A postoperative hemorrhage in patients without ASA impact was detected and treated in 5 out of 168 patients (3.0\%). The difference was statistically not significant in either model (ASA impact group vs. No ASA impact group: $\mathrm{OR}=1.0516$ [0.1187; 9.3132], $p=1.000 ; \mathrm{RR}=1.0015[0.9360 ; 1.0716]$ ). Cardiopulmonary complications were significantly more frequent in the group with ASA impact than in the group without ASA impact $(p=0.030)$. In this study continued ASA use was not associated with an increased risk of a postoperative hemorrhage. However, cardiopulmonary complications were significantly more frequent in the ASA impact group than in the No ASA impact group. Thus, ASA might relatively safely be continued in patients with increased cardiovascular risk and cases of emergency cerebrovascular surgery.
\end{abstract}

Keywords Acetylsalicylic acid $\cdot$ Aneurysm surgery $\cdot$ Clipping $\cdot$ Postoperative hemorrhage

\section{Introduction}

Low-dose Acetylsalicylic acid (ASA) is recommended as preventive treatment for many disorders, including coronary artery diseases (CAD) and stroke, as well as for patients receiving a percutaneous coronary or carotid

Michael Luchtmann

michael.luchtmann@med.ovgu.de

1 Department of Neurosurgery, Otto-von-Guericke University Magdeburg, Leipziger Str. 44, Magdeburg, Germany

2 Department of Neuroradiology, Otto-von-Guericke University Magdeburg, Leipziger Str. 44, Magdeburg, Germany artery stenting to prevent stent-thrombosis. In addition, many patients suffering from atrial fibrillation use aspirin or other anticoagulant therapies for prevention of stroke $[5,6,8,14,18,21,27,30,37,42,43,46,48,52]$.

By transfer of its acetyl group to serine residue in the platelet cyclooxygenase receptor ASA irreversibly inhibits platelet function. It prevents the configuration of thromboxane A2 and subsequenty the aggregation of platelet for the entire lifecycle (7-10 days) [19, 20, 28, 31, 35, 41]. The inhibition of platelet function ensues even at lower dosages [10, 11, 44]. Abrupt interruption of ASA use may lead to a hypercoagulability, which are associated with some of the major adverse cardiovascular events that have been reported [33]. 
ASA has been proved as a major risk factor in the development of postoperative hemorrhage following neurosurgical procedures $[36,40]$. Because postoperative rebleeding is frequently a life-threatening complication after intracranial operations, ASA is usually discontinued seven days or more prior to elective intracranial procedures $[22,28]$.

Weighting the risks of perioperative hemorrhage and cardiovascular complications of patients using ASA is a challenging task in daily neurosurgical routine. Yet, only a very limited number of studies evaluated the risk of ASA discontinuation or continuation before and after the neurosurgical treatment. There are a limited number of studies that have shown worse outcomes with pre-injury antiplatelet treatment $[12,16,23,24,49]$. However, a clear consensus on how to handle patients using ASA in the perioperative settings does not yet established [13, 17, 20, 25, 26, 32, 38, 47].

In the present study, we have evaluated the perioperative ASA management as it relates to the risk of postoperative hemorrhage and adverse cardiovascular events in patients undergoing neurosurgical treatment of ruptured and unruptured intracranial aneurysms.

\section{Methods}

This retrospective study analyzed the medical records of all consecutive patients who underwent clipping procedures at our institution between 2008 and 2018. All aneurysms were treated via "traditional" microsurgical clipping. In only one patient two aneurysm were sealed in one session. In all other SAH patients, the ruptured aneurysm only was clipped.

Clinical data on patients were obtained by retrospective chart review, and included

$-\quad$ age

- sex

- blood group

- body mass index (BMI)

- perioperative use of ASA

- hypertension

- smoking history

- laboratory parameters

- subarachnoid hemorrhage/unruptured aneurysm

- length of hospitalization

- Hunt and Hess scale

- Fisher Grade

- location and size of aneurysm

- multiplicity of aneurysms

- operative procedure

- op-duration

- blood loss

- complications (hemorrhage, deep vein thrombosis, etc.)
- peri- and postoperative Karnofsky performance status (KPS), Glasgow outcome score (GOS)

In 43 patients the data records revealed ASA in the recent medical history. Of these, 11 patients discontinued the ASA use timely prior to surgery. However, in 32 patients the ASA use was not stopped at all or timely. The common ASA dosage was $100 \mathrm{mg}$, except in three patients, were the ASA dosage was $250 \mathrm{mg}, 500 \mathrm{mg}$ and $1000 \mathrm{mg}$.

To test for possible ASA impact on postoperative hemorrhage two different statistical models utilizing Fisher's exact test were applied. The first model consisted of two groups:

- No ASA impact - patients who either had not used ASA medication at all or who had stopped the use of ASA at or before the recommended time ( $>=7$ days prior to operation)

- ASA impact - all patients who had not discontinued ASA use within the recommended time frame

The second model consisted of three groups:

- No ASA use

- Stopped ASA use ( $>=7$ days prior to operation);

- Continued ASA use (did not stop use $<7$ days prior to operation or did not stop use at all).

A postoperative hemorrhage was defined as relevant if a subsequent operation for hematoma removal was necessary. Major thromboembolic complications were defined as myocardial infarction and/or pulmonary embolism.

Data storage and statistical analyses were performed using the software package SAS University Edition (SAS Institute, Inc., Cary, New York, USA). Because the present analysis was performed in an explorative sense, it was deliberately reviewed to the full level of significance. Each $p$ value $<0.05$ therefore represented a statistically significant result. For unadjusted analyses, Fisher's exact test was applied for categorical variables, and the robust t test (Satterthwaite) was used for continuous variables, where variables with extreme deviation from normal distribution had been log transformed.

\section{Results}

In total, 200 clipping operations were performed between 2008 and 2018. In the current study, we considered the most important complication after clipping surgery and divided it into two categories: postoperative hemorrhagic events and thromboembolic events. We studied potential risk factors of hemorrhagic complications regardless of ASA status. We evaluated the effects of demographic characteristics, aneurysm characteristics, hospitalization, and surgical features. 
Table 1 - Demographic and aneurysm characteristics of patients suffered from postoperative hemorrhage

\begin{tabular}{|c|c|c|c|c|c|c|c|c|c|}
\hline \multirow[b]{2}{*}{ \# } & \multirow[b]{2}{*}{$\begin{array}{l}\text { Age } \\
\text { [years] }\end{array}$} & \multirow[b]{2}{*}{ Gender } & \multirow[b]{2}{*}{ SAH } & \multirow[b]{2}{*}{ ASA } & \multicolumn{2}{|l|}{ Hemorrhage } & \multicolumn{3}{|c|}{ Aneurysm } \\
\hline & & & & & Type & Side & Location & Side & $\begin{array}{l}\text { Size } \\
{[\mathrm{mm}]}\end{array}$ \\
\hline 1 & 78 & female & yes & $100 \mathrm{mg}$ & intracerebral & ipsilateral & $\mathrm{MCA}$ & right & 3.4 \\
\hline 2 & 57 & female & no & no & intracerebral & contralateral & MCA & right & 3.3 \\
\hline 3 & 65 & female & yes & no & subdural & ipsilateral & $\mathrm{MCA}$ & left & 4 \\
\hline 4 & 62 & female & no & no & subgaleal & ipsilateral & MCA & left & 9 \\
\hline 5 & 45 & male & yes & no & epidural & ipsilateral & $\mathrm{MCA}$ & right & 3.6 \\
\hline 6 & 63 & female & yes & no & intracerebral & ipsilateral & $\mathrm{MCA}$ & left & 5 \\
\hline
\end{tabular}

Postoperative hemorrhagic and thromboembolic complications were observed in less than $3 \%$ of the operations. Figure 2 shows two representative cases of postoperative hemorrhage. A total of 6 patients suffered a postoperative hemorrhage. Of these, one patient had used ASA (Table 1). Table 2 shows that there is no significant difference in postoperative hemorrhage occurrence in the different groups. Re-craniotomy with evacuation of a hematoma was required no more frequently in the ASA impact group than in the No ASA impact group $(p=1.0)$. As also shown in Fig. 1 and Table 2, in the case of ASA use, there is also no significant difference in the risk of postoperative hemorrhage between the three conditions ( $p=0.835$ ).

Age and sex of patients and other demographic characteristics such as body mass index (BMI), blood group, hypertension and smoking history were nearly equally distributed. There was no significant difference in patient age between the No ASA impact group ( $N=168 / 55.6 \pm 11.4$ years) and the $A S A$ impact group $(N=32 / 59.4 \pm 14.0$ years) $[p=0.150]$. These demographic characteristics are presented in Table 3 and do not impact on the postoperative hemorrhagic frequency in the different groups.

Clipping was performed in 148 cases on patients who suffered subarachnoid hemorrhage (SAH) and in 52 cases on patients who had unruptured intracranial aneurysms (UIA). Out of the 32 patients operated under the impact of ASA 24 suffered from SAH. Subsequent urgent operations prevented the timely withdrawal of ASA. In the remaining 8 patients, discontinuation of ASA would have resulted in an increased cardiovascular risk (e.g. following recent placement of coronary stents). There was no significant difference in distribution between the No ASA impact $(N=124$ SAH vs. $N=44$ UIA) and the $A S A$ impact groups $(N=24 \mathrm{SAH}$ vs. $N=8$ UIA) $[p=1,000]$. The classification according to the Hunt and Hess scale, the modified Fisher grade in patients with $\mathrm{SAH}$, and the length of hospitalization in both groups, as well as any thrombosis prophylaxis, showed no significant difference between the No ASA impact and the ASA impact groups. However, there was a significant difference in length of hospitalization (Table 4) between patients without postoperative hemorrhage ( $N=194 / 15.6 \pm 9.1$ days) and patients with postoperative hemorrhage $(N=6 / 25.0 \pm 8.7$ days) $(p=0.045)$.

With regard to a postoperative hemorrhage, aneurysm size proved to play a role and was the only statistically significant parameter $(\mathrm{N}=194: 7.1 \pm 4.6 \mathrm{~mm}$ vs. $\mathrm{N}=6: 4.7 \pm 2.2 ; p=$ 0.042 ). As shown in Table 5 , all other analyzed aneurysm characteristics did not significantly correlate with the risk of postoperative hemorrhage.

Blood loss during surgery was similar for the No ASA impact group $(197.6 \pm 46.5 \mathrm{ml})$ and the ASA-impact group $(203.9 \pm$ $40.5 \mathrm{ml} ; p=0.438$ ). The other operative parameters (Table 6), such as duration of surgery and application of temporary clipping did not play a role in the occurrence of a postoperative hemorrhage. The perioperative laboratory parameters including international normalized ratio (INR), partial thromboplastin time (PTT) [sec], thrombin time (TT) [sec] and platelet count $\left(10^{9} / \mathrm{l}\right)$ showed no significant difference between the study groups.
Table 2 - No evidence for increased risk from continued ASA use has been found

\begin{tabular}{lllllll}
\hline & & \multicolumn{5}{c}{ Hemorrhage } \\
\hline & & ASA dosage & $\sum$ & No & Yes & \\
ASA impact & mean \pm SD $[\mathrm{mg}]$ & $\mathrm{N}(\%$ column $)$ & $\mathrm{N}(\%$ row $)$ & $\mathrm{N}(\%$ row $)$ & p value \\
& & $6.5 \pm 24.8$ & $168(84.0)$ & $163(97.0)$ & $5(3.0)$ & 1.000 \\
ASA use & Yes & $145.3 \pm 172.9$ & $32(16.0)$ & $31(96.9)$ & $1(3.1)$ & \\
& No & $0.0 \pm 0.0$ & $157(78.5)$ & $152(96.8)$ & $5(3.2)$ & 0.835 \\
& Stopped & $100.0 \pm 0.0$ & $11(5.5)$ & $11(100.0)$ & $0(0.0)$ & \\
& Continued & $145.3 \pm 172.9$ & $32(16.0)$ & $31(96.9)$ & $1(3.1)$ & \\
& $\sum$ & & 200 & $194(97.0)$ & $6(3.0)$ & \\
\hline
\end{tabular}


Fig. 1 - Number of hemorrhagic complications per ASA condition. No significant difference in the risk of postoperative hemorrhage between the three conditions was obtained $(p=0.835)$

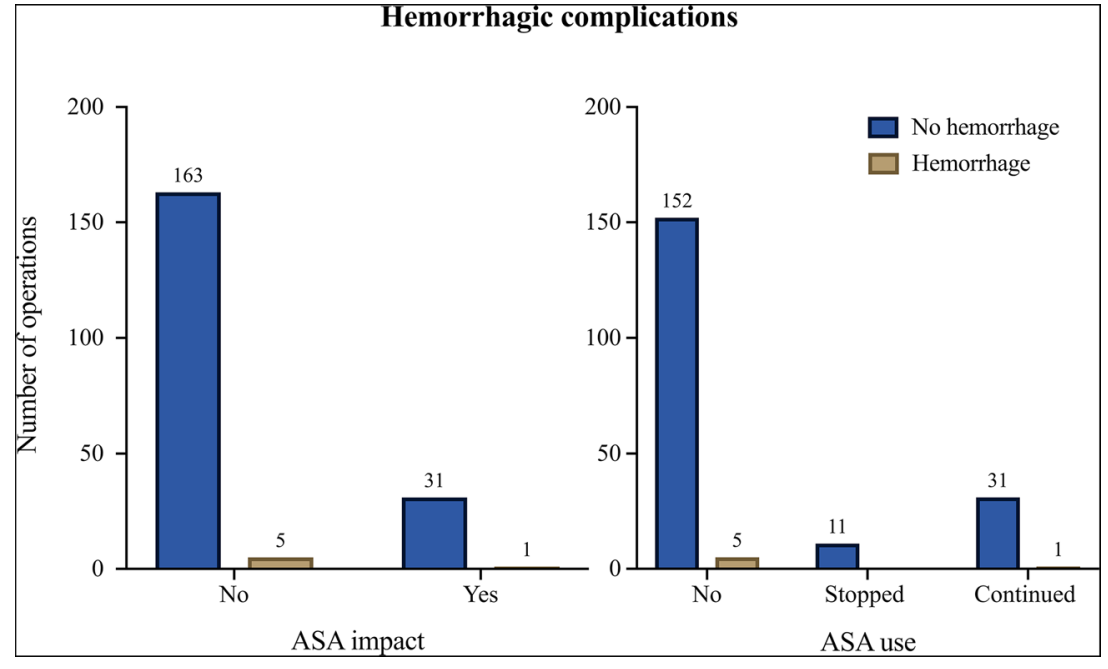

Table 7 shows the frequency of cardiopulmonary complications of the investigated patients. Five patients suffered a pulmonary embolism after a deep vein thrombosis. One of these patients had not taken ASA. In one patient the ASA medication was discontinued in time. Three patients suffered pulmonary embolism under ASA impact. This type of complication was significantly more frequent in the ASA impact group than in the No ASA impact group $(p=0.030)$. However, the occurrence of cardiopulmonary complications was independent of whether ASA use had been discontinued or not been used at all prior to surgery.

\section{Discussion}

We investigated the impact of perioperative ASA treatment on postoperative hemorrhage, thromboembolic complications and clinical parameters in patients undergoing aneurysm-clipping operations for ruptured and unruptured intracranial aneurysms. In our study cohort, we could not observe that perioperative ASA use does result in increased hemorrhagic complications for aneurysmclipping surgery.

In some studies, aneurysm characteristics such as size and posterior circulation location, as well as demographic characteristics such as patient age and case volume were seen as risk factors for surgical treatment of UIA [1-3, 34, 51, 53]. In our study, aneurysm size proved to be an independent risk factor indicating that smaller aneurysms are associated with an increased risk of postoperative hemorrhage. This observation is contrary to the findings by Nakamizo et al. [38], who did not observe an impact of aneurysms size on the rate of postoperative hemorrhage.

Nakamizo et al. [38] reveal in their study on patients undergoing craniotomy for UIA that intracranial hemorrhage was more frequent in the group that was receiving antithrombotic treatment than in the group not receiving antithrombotic drugs. In a study by Toyoda et al. [50] it was found that neither double treatment with antiplatelet inhibitors nor the addition of an antiplatelet inhibitor to

Fig. 2 - Two representative cases of postoperative hemorrhage after clipping of middle cerebral artery aneurysms: (A) intracerebral hemorrhage, (B) epidural hematoma

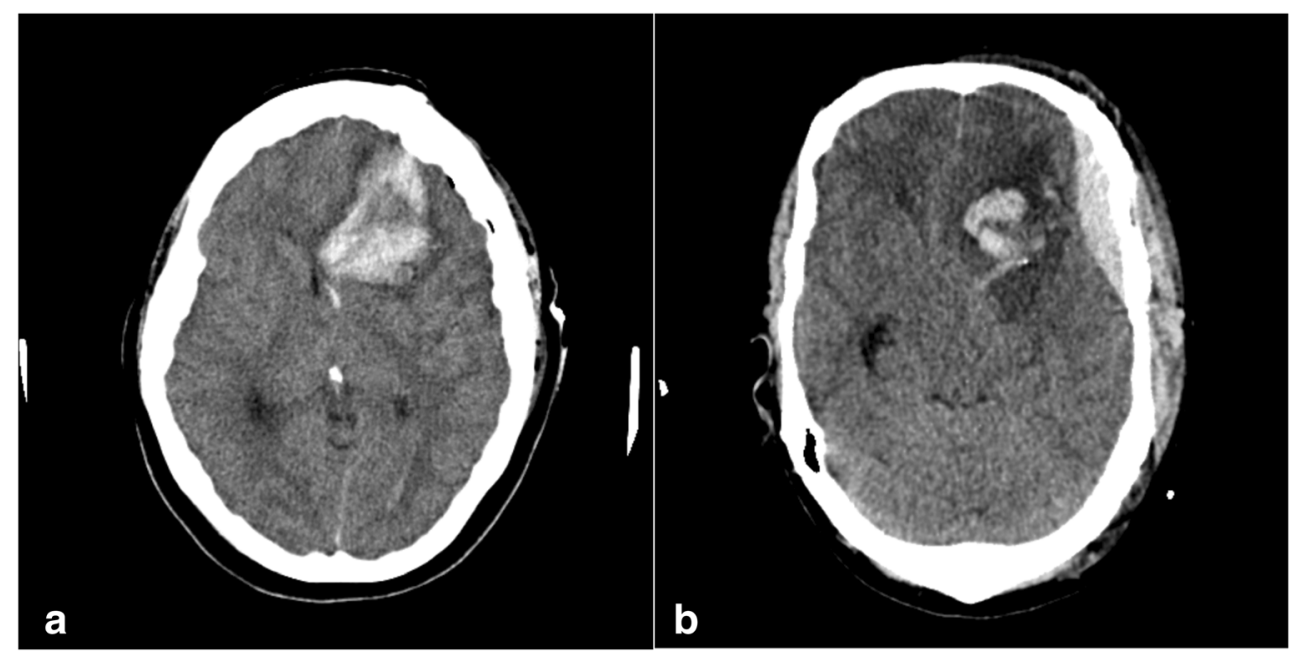


Table 3 - Demographic characteristics of the investigated patients

\begin{tabular}{|c|c|c|c|c|c|c|c|}
\hline & Operations & No ASA impact & ASA impact & p value & No hemorrhage & Hemorrhage & $p$ value \\
\hline & $\mathrm{N}(\%)$ & $\mathrm{N}(\%) /$ mean $\pm \mathrm{SD}$ & $\mathrm{N}(\%) /$ mean $\pm \mathrm{SD}$ & & $\mathrm{N}(\%) /$ mean $\pm \mathrm{SD}$ & $\mathrm{N}(\%) /$ mean $\pm \mathrm{SD}$ & \\
\hline \multicolumn{8}{|c|}{ Demographic information } \\
\hline Age [years] & 200 & $168 / 55.6 \pm 11.4$ & $32 / 59.4 \pm 14.0$ & 0.150 & $194 / 56.0 \pm 11.9$ & $6 / 61.7 \pm 10.8$ & 0.259 \\
\hline Gender & 200 & & & & & & \\
\hline female & $139(69.5)$ & $117(84.2)$ & $22(15.8)$ & 1.000 & $134(96.4)$ & $5(3.6)$ & 0.669 \\
\hline male & $61(30.5)$ & $51(83.6)$ & $10(16.4)$ & & $60(98.4)$ & $1(1.6)$ & \\
\hline Height $[\mathrm{cm}]$ & 187 & $156 / 169.1 \pm 8.1$ & $31 / 168.0 \pm 9.9$ & 0.574 & $182 / 168.9 \pm 8.0$ & $5 / 170.2 \pm 18.7$ & 0.884 \\
\hline Weight $(\mathrm{kg})$ & 187 & $156 / 74.2 \pm 14.1$ & $31 / 75.5 \pm 14.0$ & 0.638 & $182 / 74.3 \pm 14.1$ & $5 / 77.4 \pm 14.6$ & 0.665 \\
\hline Body mass index & 187 & $156 / 25.9 \pm 4.6$ & $31 / 26.7 \pm 4.5$ & 0.355 & $182 / 26.0 \pm 4.6$ & $5 / 26.9 \pm 4.5$ & 0.690 \\
\hline Blood group (AB0) & 180 & & & & & & \\
\hline A & $71(39.4)$ & $60(84.5)$ & $11(15.5)$ & 0.483 & $71(100.0)$ & $0(0.0)$ & 0.100 \\
\hline $\mathrm{B}$ & $25(13.9)$ & $23(92.0)$ & $2(8.0)$ & & $24(96.0)$ & $1(4.0)$ & \\
\hline $\mathrm{AB}$ & $9(5.0)$ & $8(88.9)$ & $1(11.1)$ & & $8(88.9)$ & $1(11.1)$ & \\
\hline 0 & 75 (41.7) & $59(78.7)$ & $16(21.3)$ & & $72(96.0)$ & $3(4.0)$ & \\
\hline Blood group (rhesus) & 180 & & & & & & \\
\hline $\mathrm{Rh}+$ & $155(86.1)$ & $126(81.3)$ & $29(18.7)$ & 0.083 & $151(97.4)$ & $4(2.6)$ & 0.531 \\
\hline $\mathrm{Rh}-$ & $25(13.9)$ & $24(96.0)$ & $1(4.0)$ & & $24(96.0)$ & $1(4.0)$ & \\
\hline Hypertension & 200 & & & & & & \\
\hline Yes & $89(44.5)$ & $72(80.9)$ & $17(19.1)$ & 0.334 & 87 (97.8) & $2(2.2)$ & 0.694 \\
\hline No & $111(55.5)$ & $96(86.5)$ & $15(13.5)$ & & $107(96.4)$ & $4(3.6)$ & \\
\hline Smoker & 200 & & & & & & \\
\hline Yes & $70(35.0)$ & $58(82.9)$ & $12(17.1)$ & 0.840 & $68(97.1)$ & $2(2.9)$ & 1.000 \\
\hline No & $130(65.0)$ & $110(84.6)$ & $20(15.4)$ & & $126(96.9)$ & $4(3.1)$ & \\
\hline
\end{tabular}

warfarin placed patients at increased risk of perioperative bleeding. An aggravated postoperative hemorrhage risk due to the intake of ASA could not be confirmed in our study. Hanalioglu et al. [20] demonstrated - similar to our study - that perioperative ASA use was not associated with an increased rate of hemorrhagic complications after intracranial tumor surgery. Unsurprisingly, we found a significant difference in length of hospitalization time between those patients with postoperative hemorrhage compared to patients without hemorrhage. It is relatable that for patients with postoperative hemorrhage, the recovery phase and thus the length of hospital stay is longer.

In our study, cardiopulmonary complications were significantly more frequent in the ASA impact group than in the No ASA impact group. Some studies suggest that discontinuing ASA medication in patients receiving antithrombotic treatment can pose a significant risk factor of both thromboembolic and bleeding events $[4,15]$. The international, randomized, placebo-controlled trial (POISE-2) revealed that the perioperative use of ASA had no significant impact on mortality, but increased the risk of major hemorrhage [9]. Our results are somehow conflicting with the assumption of Gerstein et al. [15] who supposed that abrupt discontinuation of long-term ASA usage could lead to platelet rebound phenomena resulting in increased risk of thrombosis. The role of ASA (-withdraw) in the context of deep venous thrombosis and pulmonary embolism after SAH remains unclear. During the study period, postoperative thrombosis prophylaxis using low molecular weight heparin was not administrated routinely for cranial surgery, thus, based on our data reliable conclusions cannot be drawn [45]. For the prevention of venous thromboembolism most patients used compression stockings only.

Recent guidelines in anesthesiology and cardiology recommend perioperative ASA continuation in patients with low to moderate bleeding risk and high cardiovascular risk [7, 39]. Intracranial operations as well as intramedullary spinal surgeries are considered high-risk bleeding procedures and are therefore excluded from recommendations for ASA continuation, even in patients with a high cardiovascular risk [39]. A national survey of neurosurgeons in Germany studying the use of ASA prior to intracranial operations revealed that $77.5 \%$ of those responding believed that patients taking low-dose ASA had an increased risk of major perioperative 
Table 4 - Clinical parameters. Unsurprisingly, patients with postoperative hemorrhaging spent a significantly longer time in hospital

\begin{tabular}{|c|c|c|c|c|c|c|c|}
\hline & Operations & No ASA impact & ASA impact & p value & No hemorrhage & Hemorrhage & $p$ value \\
\hline & $\mathrm{N}(\%)$ & $\mathrm{N}(\%) /$ mean $\pm \mathrm{SD}$ & $\mathrm{N}(\%) /$ mean $\pm \mathrm{SD}$ & & $\mathrm{N}(\%) /$ mean $\pm \mathrm{SD}$ & $\mathrm{N}(\%) /$ mean $\pm \mathrm{SD}$ & \\
\hline \multicolumn{8}{|l|}{ Hospitalization/SAH } \\
\hline Duration [days] & 200 & $168 / 15.9 \pm 9.5$ & $32 / 16.2 \pm 7.7$ & 0.845 & $194 / 15.6 \pm 9.1$ & $6 / 25.0 \pm 8.7$ & 0.045 \\
\hline Subarachnoid hemorrhage & 200 & & & & & & \\
\hline Yes & $148(74.0)$ & $124(83.8)$ & $24(16.2)$ & \multirow[t]{2}{*}{1.000} & $144(97.3)$ & $4(2.7)$ & \multirow[t]{2}{*}{0.651} \\
\hline UIA / No & $52(26.0)$ & $44(84.6)$ & $8(15.4)$ & & $50(96.1)$ & $2(3.9)$ & \\
\hline Hunt and Hess scale & 138 & & & & & & \\
\hline 1 & $42(30.4)$ & $35(83.3)$ & $7(16.7)$ & \multirow[t]{5}{*}{0.407} & $40(95.2)$ & $2(4.8)$ & \multirow[t]{5}{*}{0.296} \\
\hline 2 & $24(17.4)$ & $22(91.7)$ & $2(8.3)$ & & $22(91.7)$ & $2(8.3)$ & \\
\hline 3 & $17(12.3)$ & $12(70.6)$ & $5(29.4)$ & & $17(100.0)$ & $0(0.0)$ & \\
\hline 4 & $43(31.2)$ & $35(81.4)$ & $8(18.6)$ & & $43(100)$ & $0(0.0)$ & \\
\hline 5 & $12(8.7)$ & $11(91.7)$ & $5(8.3)$ & & $12(100.0)$ & $0(0.0)$ & \\
\hline Fisher grade (modified) & 137 & & & & & & \\
\hline 0 & $2(1.5)$ & $2(100.0)$ & $0(0.0)$ & \multirow[t]{5}{*}{0.649} & $2(100.0)$ & $0(0.0)$ & \multirow[t]{5}{*}{0.305} \\
\hline 1 & $4(3.0)$ & $4(100.0)$ & $0(0.0)$ & & $4(100.0)$ & $0(0.0)$ & \\
\hline 2 & $21(15.3)$ & $18(85.7)$ & $3(14.3)$ & & $20(95.2)$ & $1(4.8)$ & \\
\hline 3 & $53(38.7)$ & $46(86.8)$ & $7(13.2)$ & & $50(94.3)$ & $3(5.7)$ & \\
\hline 4 & 57 (41.6) & $44(77.2)$ & $13(22.8)$ & & $57(100.0)$ & $0(0.0)$ & \\
\hline Thromboprophylaxis & 188 & & & & & & \\
\hline No & $176(93.6)$ & $149(84.7)$ & $27(15.3)$ & \multirow[t]{2}{*}{0.411} & $170(96.6)$ & $6(3.4)$ & \multirow[t]{2}{*}{1.000} \\
\hline Yes & $12(6.4)$ & $9(75.0)$ & $3(25.0)$ & & $12(100.0)$ & $0(0.0)$ & \\
\hline
\end{tabular}

Table 5 - Aneurysm characteristics. The size of the aneurysm might be a factor influencing the risk of postoperative hemorrhage

\begin{tabular}{|c|c|c|c|c|c|c|c|}
\hline & Operations & No ASA impact & ASA impact & p value & No hemorrhage & Hemorrhage & $p$ value \\
\hline & $\mathrm{N}(\%)$ & $\mathrm{N}(\%) /$ mean $\pm \mathrm{SD}$ & $\mathrm{N}(\%) /$ mean $\pm \mathrm{SD}$ & & $\mathrm{N}(\%) /$ mean $\pm \mathrm{SD}$ & $\mathrm{N}(\%) /$ mean $\pm \mathrm{SD}$ & \\
\hline \multicolumn{8}{|c|}{ Aneurysm characteristics } \\
\hline Aneurysm location & 200 & & & & & & \\
\hline MCA & $134(67.0)$ & $109(81.3)$ & $25(18.7)$ & \multirow[t]{7}{*}{0.155} & $128(95.5)$ & $6(4.5)$ & \multirow[t]{7}{*}{0.874} \\
\hline Acom & $31(15.5)$ & $29(93.6)$ & $2(6.4)$ & & $31(100.0)$ & $0(0.0)$ & \\
\hline $\mathrm{ACA}$ & $16(8.0)$ & $15(93.7)$ & $1(6.3)$ & & $16(100.0)$ & $0(0.0)$ & \\
\hline $\mathrm{ACI}$ & $12(6.0)$ & $10(83.3)$ & $2(16.7)$ & & $12(100.0)$ & $0(0.0)$ & \\
\hline PICA & $3(1.5)$ & $1(33.3)$ & $2(66.7)$ & & $3(100.0)$ & $0(0.0)$ & \\
\hline Pcom & $2(1.0)$ & $2(100.0)$ & $0(0.0)$ & & $2(100.0)$ & $0(0.0)$ & \\
\hline VA & $2(1.0)$ & $2(100.0)$ & $0(0.0)$ & & $2(100.0)$ & $0(0.0)$ & \\
\hline Circulation & 200 & & & & & & \\
\hline Anterior & $195(97.5)$ & $165(84.6)$ & $30(15.4)$ & \multirow[t]{2}{*}{0.182} & $189(96.9)$ & $6(3.1)$ & \multirow[t]{2}{*}{1.000} \\
\hline Posterior & $5(2.5)$ & $3(60.0)$ & $2(40.0)$ & & $5(100.0)$ & $0(0.0)$ & \\
\hline Hemisphere & 200 & & & & & & \\
\hline Right & $115(57.5)$ & $97(84.3)$ & $18(15.7)$ & \multirow[t]{2}{*}{1.000} & $112(97.4)$ & $3(2.6)$ & \multirow[t]{2}{*}{0.788} \\
\hline Left & $85(42.5)$ & $71(83.5)$ & $14(16.5)$ & & $82(96.5)$ & $3(3.5)$ & \\
\hline Size $[\mathrm{mm}]$ & 200 & $168 / 7.1 \pm 4.6$ & $32 / 7.0 \pm 4.0$ & 0.992 & $194(7.1 \pm 4.6)$ & $6(4.7 \pm 2.2)$ & 0.042 \\
\hline \multicolumn{8}{|l|}{ Number of aneurysms } \\
\hline Single & $128(64.0)$ & $110(85.9)$ & $18(14.1)$ & \multirow[t]{2}{*}{0.323} & $122(95.3)$ & $6(4.7)$ & \multirow[t]{2}{*}{0.089} \\
\hline Multiple & $72(36.0)$ & $58(80.6)$ & $14(19.4)$ & & $72(100.0)$ & $0(0.0)$ & \\
\hline Shape of aneurysm & 200 & & & & & & \\
\hline Saccular & $144(72.0)$ & $118(81.9)$ & $26(18.1)$ & \multirow[t]{2}{*}{0.283} & $142(98.6)$ & $2(1.4)$ & \multirow[t]{2}{*}{0.053} \\
\hline Multilobar & $56(28.0)$ & $50(89.3)$ & $6(10.7)$ & & $52(92.9)$ & $4(7.1)$ & \\
\hline
\end{tabular}


Table 6 - Perioperative parameters have no significant influence on the risk of postoperative hemorrhaging

\begin{tabular}{|c|c|c|c|c|c|c|c|}
\hline & Operations & No ASA impact & ASA impact & p value & No hemorrhage & Hemorrhage & p value \\
\hline & $\mathrm{N}(\%)$ & $\mathrm{N}(\%) /$ mean $\pm \mathrm{SD}$ & $\mathrm{N}(\%) /$ mean $\pm \mathrm{SD}$ & & $\mathrm{N}(\%) /$ mean $\pm \mathrm{SD}$ & $\mathrm{N}(\%) /$ mean $\pm \mathrm{SD}$ & \\
\hline \multicolumn{8}{|l|}{ Operative parameters } \\
\hline Operation time [min] & 200 & $168 / 197.6 \pm 46.5$ & $32 / 203.9 \pm 40.5$ & 0.438 & $194 / 198.6 \pm 46.0$ & $6 / 197.7 \pm 27.0$ & 0.938 \\
\hline Temporary clipping (sec) & 48 & $37 / 143.2 \pm 125.6$ & $11 / 245.4 \pm 165.6$ & 0.080 & $46 / 164.5 \pm 141.8$ & $2 / 215.5 \pm 142.1$ & 0.701 \\
\hline Blood loss (ml) & 185 & $154 / 365.2 \pm 341$ & $31 / 348.5 \pm 220.5$ & 0.730 & $180 / 364.7 \pm 327.0$ & $5 / 282.6 \pm 138.9$ & 0.270 \\
\hline \multicolumn{8}{|l|}{ Laboratory parameters } \\
\hline $\begin{array}{l}\text { International normalized ratio } \\
\text { (INR) }\end{array}$ & 173 & $144 / 1.0 \pm 0.1$ & $29 / 1.0 \pm 0.1$ & 0.852 & $168 / 1.0 \pm 0.1$ & $5 / 1.0 \pm 0.1$ & 0.945 \\
\hline $\begin{array}{l}\text { Partial thromboplastin time (PTT) } \\
\text { [sec] }\end{array}$ & 200 & $168 / 28.0 \pm 2.4$ & $32 / 27.5 \pm 3.0$ & 0.383 & $194 / 27.9 \pm 2.5$ & $6 / 28.0 \pm 2.4$ & 1.000 \\
\hline Thrombin time (TT) [sec] & 192 & $161 / 16.0 \pm 2.0$ & $31 / 15.9 \pm 2.1$ & 0.823 & $186 / 16.0 \pm 2.1$ & $6 / 16.1 \pm 0.7$ & 0.800 \\
\hline Platelet count $\left(10^{9} / 1\right)$ & 200 & $168 / 261.8 \pm 85.3$ & $32 / 280.4 \pm 90.7$ & 0.289 & $194 / 266.0 \pm 87.0$ & $6 / 225.8 \pm 45.7$ & 0.148 \\
\hline \multicolumn{8}{|l|}{ Performance status/Outcome } \\
\hline KPS postoperative & 199 & $168 / 72.3 \pm 28.0$ & $31 / 64.8 \pm 3.2$ & 0.245 & $193 / 71.5 \pm 29.0$ & $6 / 60.0 \pm 26.1$ & 0.334 \\
\hline Glasgow outcome score (GOS) & 199 & $168 / 4.2 \pm 1.1$ & $31 / 3.7 \pm 1.4$ & 0.095 & $193 / 4.1 \pm 1.2$ & $6 / 4.0 \pm 1.3$ & 0.843 \\
\hline
\end{tabular}

hemorrhage [28]. Of those respondents, 58\% reported personal experience with perioperative bleeding. The same group also reported the results of a study on spinal surgery that found a similar percentage of perioperative bleeding occurrence. Nevertheless, in a related study only a small fraction $(5 \%)$ of neurosurgeons would agree to perform spinal surgery under ASA medication [29].

However, some limiting aspects beyond the obvious flaws of retrospective study designs have to be discussed. In the reported period functional platelet testing was not available in time for most patients. Therefore, statistical analysis was not feasible and reliable conclusions regarding ASA non-responder were not possible. Furthermore, the treatment strategies were different in several cases, particularly in patients with multiple aneurysms. However, due to the relatively low incidence of posthemorrhagic events subgroup analysis were not useful.

\section{Conclusion}

In this study continued ASA use was not associated with an increased risk of a postoperative hemorrhage in patients undergoing aneurysm surgery. In contrast, cardiopulmonary complications were significantly more frequent in the ASA-impact group than in the No-ASA-impact group. However, in patients with increased cardiovascular risk and in the case of emergency surgery, ASA might relatively safe be continued. Aneurysms size was found to be an independent risk factor regarding the incidence of postoperative hemorrhage. Prospective randomized studies are necessary to evaluate the risks and safety of the perioperative use of ASA in neurosurgical procedures with respect on epidemiological changes and increased use of antiplatelet treatment or anticoagulation.
Table 7 - Cardiopulmonary complications were significantly more frequent in the ASA-impact group than in the No-ASA-impact group. However, a short-term discontinuation of ASA treatment seems to have had no influence on the incidence of perioperative thromboembolic complications

\begin{tabular}{|c|c|c|c|c|c|}
\hline & & \multicolumn{4}{|c|}{ Cardiopulmonary complications } \\
\hline & & $\sum$ & No & Yes & \\
\hline & & $\mathrm{N}(\%$ column $)$ & $\mathrm{N}(\%$ row $)$ & $\mathrm{N}$ (\% row) & p value \\
\hline \multirow[t]{2}{*}{ ASA impact } & No & $168(84.0)$ & $166(98.8)$ & $2(1.2)$ & \multirow[t]{2}{*}{$\mathbf{0 . 0 3 0}$} \\
\hline & Yes & $32(16.0)$ & $29(90.6)$ & $3(9.4)$ & \\
\hline \multirow[t]{4}{*}{ ASA use } & No & $157(78.5)$ & $156(99.4)$ & $1(0.6)$ & \multirow[t]{4}{*}{0.009} \\
\hline & Stopped & $11(5.5)$ & $10(90.9)$ & $1(9.1)$ & \\
\hline & Continued & $32(16.0)$ & $29(90.6)$ & $3(9.4)$ & \\
\hline & $\sum$ & 200 & $194(97.0)$ & $6(3.0)$ & \\
\hline \multirow[t]{3}{*}{ ASA use } & Continued & $32(74.4)$ & $29(90.6)$ & $3(9.4)$ & \multirow[t]{3}{*}{1.000} \\
\hline & Stopped & $11(25.6)$ & $10(90.9)$ & $1(9.1)$ & \\
\hline & $\sum$ & 43 & $39(90.7)$ & $4(9.3)$ & \\
\hline
\end{tabular}


Authors' contributions Conceptualization: Ali Rashidi, Michael Luchtmann.

Data collection: Ali Rashidi, Michael Luchtmann, Martin Skalej.

Formal analysis: Ali Rashidi, Michael Luchtmann.

Supervision: Martin Skalej, I. Erol Sandalcioglu, Michael Luchtmann.

Writing - original draft: Ali Rashidi, Michael Luchtmann.

Writing - review \& editing: Nadine Lilla, I. Erol Sandalcioglu.

Funding Open Access funding enabled and organized by Projekt DEAL.

Data availability Not applicable.

\section{Compliance with ethical standards}

Conflict of interest The authors below certify that they have no affiliations with or involvement in any organization or entity with any financial interest (such as honoraria; educational grants; participation in speakers' bureaus; membership, employment, consultancies, stock ownership, or other equity interest; and expert testimony or patent-licensing arrangements), or nonfinancial interest (such as personal or professional relationships, affiliations, knowledge or beliefs) in the subject matter or materials discussed in this manuscript.

Ethics approval and consent to participate The presented study was conducted in compliance with the national legislation and the code of ethical principles for medical research involving human subjects of the world medical association (Declaration of Helsinki). The collection, analysis and publication of retrospective clinical data is generally approved by the ethics committee of the Medical Faculty of the Otto-von-Guericke University of Magdeburg. The study was approved and registered by the institutional review board (IRB) of the Medical Faculty of the Otto-vonGuericke University of Magdeburg (Register\#: R0320). Necessity for patient's informed consent was waived by the IRB.

Consent for publication The Author transfers to Springer (respective to owner if other than Springer and for U.S. government employees: to the extent transferable) the non-exclusive publication rights and he warrants that his/her contribution is original and that he/she has full power to make this grant. The author signs for and accepts responsibility for releasing this material on behalf of any and all co-authors. This transfer of publication rights covers the non-exclusive right to reproduce and distribute the article, including reprints, translations, photographic reproductions, microform, electronic form (offline, online) or any other reproductions of similar nature.

\section{Code availability Not applicable.}

Open Access This article is licensed under a Creative Commons Attribution 4.0 International License, which permits use, sharing, adaptation, distribution and reproduction in any medium or format, as long as you give appropriate credit to the original author(s) and the source, provide a link to the Creative Commons licence, and indicate if changes were made. The images or other third party material in this article are included in the article's Creative Commons licence, unless indicated otherwise in a credit line to the material. If material is not included in the article's Creative Commons licence and your intended use is not permitted by statutory regulation or exceeds the permitted use, you will need to obtain permission directly from the copyright holder. To view a copy of this licence, visit http://creativecommons.org/licenses/by/4.0/.

\section{References}

1. Alshekhlee A, Mehta S, Edgell RC, Vora N, Feen E, Mohammadi A, Kale SP, Cruz-Flores S (2010) Hospital mortality and complications of electively clipped or coiled unruptured intracranial aneurysm. Stroke 41:1471-1476. https://doi.org/10.1161/strokeaha. 110.580647

2. Barker FG 2nd, Amin-Hanjani S, Butler WE, Hoh BL, Rabinov JD, Pryor JC, Ogilvy CS, Carter BS (2004) Age-dependent differences in short-term outcome after surgical or endovascular treatment of unruptured intracranial aneurysms in the United States, 1996-2000. Neurosurgery 54:18-28; discussion 28-30. https://doi.org/10.1227/ 01.neu.0000097195.48840.c4

3. Brinjikji W, Rabinstein AA, Lanzino G, Kallmes DF, Cloft HJ (2011) Effect of age on outcomes of treatment of unruptured cerebral aneurysms: a study of the National Inpatient Sample 20012008. Stroke 42:1320-1324. https://doi.org/10.1161/strokeaha. 110.607986

4. Burger W, Chemnitius JM, Kneissl GD, Rucker G (2005) Lowdose aspirin for secondary cardiovascular prevention - cardiovascular risks after its perioperative withdrawal versus bleeding risks with its continuation - review and meta-analysis. J Intern Med 257: 399-414. https://doi.org/10.1111/j.1365-2796.2005.01477.x

5. Cohen AT, Imfeld S, Markham J, Granziera S (2015) The use of aspirin for primary and secondary prevention in venous thromboembolism and other cardiovascular disorders. Thromb Res 135: 217-225. https://doi.org/10.1016/j.thromres.2014.11.036

6. Collaborative meta-analysis of randomised trials of antiplatelet therapy for prevention of death, myocardial infarction, and stroke in high risk patients (2002). BMJ (Clinical research ed) 324:71-86. doi:https://doi.org/10.1136/bmj.324.7329.71

7. Darvish-Kazem S, Douketis JD (2012) Perioperative management of patients having noncardiac surgery who are receiving anticoagulant or antiplatelet therapy: an evidence-based but practical approach. Semin Thromb Hemost 38:652-660. https://doi.org/10. $1055 / \mathrm{s}-0032-1326781$

8. de Gaetano G (2001) Low-dose aspirin and vitamin E in people at cardiovascular risk: a randomised trial in general practice. Collaborative Group of the Primary Prevention Project. Lancet (London, England) 357:89-95. https://doi.org/10.1016/s01406736(00)03539-x

9. Devereaux PJ, Mrkobrada M, Sessler DI, Leslie K, Alonso-Coello P, Kurz A, Villar JC, Sigamani A, Biccard BM, Meyhoff CS, Parlow JL, Guyatt G, Robinson A, Garg AX, Rodseth RN, Botto F, Lurati Buse G, Xavier D, Chan MT, Tiboni M, Cook D, Kumar PA, Forget P, Malaga G, Fleischmann E, Amir M, Eikelboom J, Mizera R, Torres D, Wang CY, VanHelder T, Paniagua P, Berwanger O, Srinathan S, Graham M, Pasin L, Le Manach Y, Gao P, Pogue J, Whitlock R, Lamy A, Kearon C, Baigent C, Chow C, Pettit S, Chrolavicius S, Yusuf S (2014) Aspirin in patients undergoing noncardiac surgery. N Engl J Med 370:1494 1503. https://doi.org/10.1056/NEJMoa1401105

10. Doutremepuich C, de Seze O, Le Roy D, Lalanne MC, Anne MC (1990) Aspirin at very ultra low dosage in healthy volunteers: effects on bleeding time, platelet aggregation and coagulation. Haemostasis 20:99-105. https://doi.org/10.1159/000216114

11. Epp K, Nolte H (1993) Prolongation and normalization of bleeding time during therapy with different doses of acetylsalicylic acid. Anaesthesist 42:300-304

12. Fabbri A, Servadei F, Marchesini G, Stein SC, Vandelli A (2010) Predicting intracranial lesions by antiplatelet agents in subjects with mild head injury. J Neurol Neurosurg Psychiatry 81:1275-1279. https://doi.org/10.1136/jnnp.2009.197467

13. Forster MT, Mathe AK, Senft C, Scharrer I, Seifert V, Gerlach R (2010) The influence of preoperative anticoagulation on outcome 
and quality of life after surgical treatment of chronic subdural hematoma. Journal of clinical neuroscience : official journal of the Neurosurgical Society of Australasia 17:975-979. https://doi.org/ 10.1016/j.jocn.2009.11.023

14. Gage BF, van Walraven C, Pearce L, Hart RG, Koudstaal PJ, Boode BS, Petersen P (2004) Selecting patients with atrial fibrillation for anticoagulation: stroke risk stratification in patients taking aspirin. Circulation 110:2287-2292. https://doi.org/10.1161/01.cir. 0000145172.55640 .93

15. Gerstein NS, Schulman PM, Gerstein WH, Petersen TR, Tawil I (2012) Should more patients continue aspirin therapy perioperatively?: clinical impact of aspirin withdrawal syndrome. Ann Surg 255:811-819. https://doi.org/10.1097/SLA. 0b013e318250504e

16. Grandhi R, Harrison G, Voronovich Z, Bauer J, Chen SH, Nicholas D, Alarcon LH, Okonkwo DO (2015) Preinjury warfarin, but not antiplatelet medications, increases mortality in elderly traumatic brain injury patients. The journal of trauma and acute care surgery 78:614-621. https://doi.org/10.1097/ta.0000000000000542

17. Guha D, Coyne S, Macdonald RL (2016) Timing of the resumption of antithrombotic agents following surgical evacuation of chronic subdural hematomas: a retrospective cohort study. J Neurosurg 124: 750-759. https://doi.org/10.3171/2015.2.jns141889

18. Guyatt GH, Akl EA, Crowther M, Gutterman DD, Schuunemann HJ (2012) Executive summary: antithrombotic therapy and prevention of thrombosis, 9th ed: American College of Chest Physicians Evidence-Based Clinical Practice Guidelines. Chest 141:7s-47s. https://doi.org/10.1378/chest.1412S3

19. Hall R, Mazer CD (2011) Antiplatelet drugs: a review of their pharmacology and management in the perioperative period. Anesth Analg 112:292-318. https://doi.org/10.1213/ANE. 0b013e318203f38d

20. Hanalioglu S, Sahin B, Sahin OS, Kozan A, Ucer M, Cikla U, Goodman SL, Baskaya MK (2019) Effect of perioperative aspirin use on hemorrhagic complications in elective craniotomy for brain tumors: results of a single-center, retrospective cohort study. J Neurosurg 132:1-10. https://doi.org/10.3171/2018.12.jns182483

21. Hayden M, Pignone M, Phillips C, Mulrow C (2002) Aspirin for the primary prevention of cardiovascular events: a summary of the evidence for the U.S. preventive services task force. Ann Intern Med 136:161-172. https://doi.org/10.7326/0003-4819-136-2200201150-00016

22. James DN, Fernandes JR, Calder I, Smith M (1997) Low-dose aspirin and intracranial surgery. A survey of the opinions of consultant neuroanaesthetists in the UK Anaesthesia 52:169-172. https://doi.org/10.1111/j.1365-2044.1997.67-az0056.x

23. Joseph B, Aziz H, Pandit V, Kulvatunyou N, Hashmi A, Tang A, Sadoun M, O'Keeffe T, Vercruysse G, Green DJ, Friese RS, Rhee P (2014) A three-year prospective study of repeat head computed tomography in patients with traumatic brain injury. J Am Coll Surg 219:45-51. https://doi.org/10.1016/j.jamcollsurg.2013.12.062

24. Joseph B, Aziz H, Pandit V, Kulvatunyou N, O'Keeffe T, Tang A, Wynne J, Hashmi A, Vercruysse G, Friese RS, Rhee P (2014) Lowdose aspirin therapy is not a reason for repeating head computed tomographic scans in traumatic brain injury: a prospective study. $\mathrm{J}$ Surg Res 186:287-291. https://doi.org/10.1016/j.jss.2013.08.009

25. Kamenova M, Lutz K, Schaedelin S, Fandino J, Mariani L, Soleman J (2016) Does early resumption of low-dose aspirin after evacuation of chronic subdural hematoma with Burr-hole drainage Lead to higher recurrence rates? Neurosurgery 79:715-721. https:// doi.org/10.1227/neu.0000000000001393

26. Kamenova M, Nevzati E, Lutz K, Dolp A, Fandino J, Mariani L, Soleman J (2017) Burr-hole drainage for chronic subdural hematoma under low-dose acetylsalicylic acid: a comparative risk analysis study. World neurosurgery 100:594-600. https://doi.org/10.1016/j. wneu.2017.01.065
27. Kiberd MB, Hall RI (2015) Aspirin in the perioperative period: a review of the recent literature. Curr Opin Anaesthesiol 28:349-355. https://doi.org/10.1097/aco.0000000000000200

28. Korinth MC (2006) Low-dose aspirin before intracranial surgeryresults of a survey among neurosurgeons in Germany. Acta Neurochir 148:1189-1196; discussion 1196. https://doi.org/10. 1007/s00701-006-0868-4

29. Korinth MC, Gilsbach JM, Weinzierl MR (2007) Low-dose aspirin before spinal surgery: results of a survey among neurosurgeons in Germany. Eur Spine J 16:365-372. https://doi.org/10.1007/ s00586-006-0216-7

30. Lee AT, Gagnidze A, Pan SR, Sookplung P, Nair B, Newman SF, Ben-Ari A, Zaky A, Cain K, Vavilala MS, Rozet I (2017) Preoperative low-dose aspirin exposure and outcomes after emergency neurosurgery for traumatic intracranial hemorrhage in elderly patients. Anesth Analg 125:514-520. https://doi.org/10.1213/ane. 0000000000002053

31. Levi MM, Vink R, de Jonge E (2002) Management of bleeding disorders by prohemostatic therapy. Int J Hematol 76(Suppl 2): 139-144. https://doi.org/10.1007/bf03165104

32. Lindvall P, Koskinen LO (2009) Anticoagulants and antiplatelet agents and the risk of development and recurrence of chronic subdural haematomas. Journal of clinical neuroscience : official journal of the Neurosurgical Society of Australasia 16:1287-1290. https:// doi.org/10.1016/j.jocn.2009.01.001

33. Lordkipanidze M, Diodati JG, Pharand C (2009) Possibility of a rebound phenomenon following antiplatelet therapy withdrawal: a look at the clinical and pharmacological evidence. Pharmacol Ther 123:178-186. https://doi.org/10.1016/j.pharmthera.2009.03.019

34. Mahaney K, Brown R, Meissner I, Piepgras D, Huston J, Zhang J, Torner J (2014) Age-related differences in unruptured intracranial aneurysms: 1-year outcomes. J Neurosurg 121:1-15. https://doi. org/10.3171/2014.6.JNS121179

35. Mannucci PM (2000) Desmopressin (DDAVP) in the treatment of bleeding disorders: the first twenty years. Haemophilia : the official journal of the World Federation of Hemophilia 6(Suppl 1):60-67. https://doi.org/10.1046/j.1365-2516.2000.00059.x

36. Merriman E, Bell W, Long DM (1979) Surgical postoperative bleeding associated with aspirin ingestion. Report of two cases Journal of neurosurgery 50:682-684. https://doi.org/10.3171/jns. 1979.50.5.0682

37. Meschia JF, Bushnell C, Boden-Albala B, Braun LT, Bravata DM, Chaturvedi S, Creager MA, Eckel RH, Elkind MS, Fornage M, Goldstein LB, Greenberg SM, Horvath SE, Iadecola C, Jauch EC, Moore WS, Wilson JA (2014) Guidelines for the primary prevention of stroke: a statement for healthcare professionals from the American Heart Association/American Stroke Association. Stroke 45:3754-3832. https://doi.org/10.1161/str.0000000000000046

38. Nakamizo A, Michiwaki Y, Kawano Y, Amano T, Matsuo S, Fujioka Y, Tsumoto T, Yasaka M, Okada Y (2017) Impact of antithrombotic treatment on clinical outcomes after craniotomy for unruptured intracranial aneurysm. Clin Neurol Neurosurg 161: 93-97. https://doi.org/10.1016/j.clineuro.2017.08.016

39. Oprea AD, Popescu WM (2013) Perioperative management of antiplatelet therapy. Br J Anaesth 111(Suppl 1):i3-i17. https://doi.org/ $10.1093 / \mathrm{bja} / \mathrm{aet} 402$

40. Palmer JD, Sparrow OC, Iannotti F (1994) Postoperative hematoma: a 5-year survey and identification of avoidable risk factors. Neurosurgery 35:1061-1064; discussion 1064-1065. https://doi. org/10.1227/00006123-199412000-00007

41. Patrono C, Coller B, FitzGerald GA, Hirsh J, Roth G (2004) Platelet-active drugs: the relationships among dose, effectiveness, and side effects: the seventh ACCP conference on antithrombotic and thrombolytic therapy. Chest 126:234s-264s. https://doi.org/10. 1378/chest.126.3_suppl.234S 
42. Perk J, De Backer G, Gohlke H, Graham I, Reiner Z, Verschuren WM, Albus C, Benlian P, Boysen G, Cifkova R, Deaton C, Ebrahim S, Fisher M, Germano G, Hobbs R, Hoes A, Karadeniz S, Mezzani A, Prescott E, Ryden L, Scherer M, Syvanne M, Op Reimer WJ, Vrints C, Wood D, Zamorano JL, Zannad F (2012) European guidelines on cardiovascular disease prevention in clinical practice (version 2012) : the fifth joint task force of the European society of cardiology and other societies on cardiovascular disease prevention in clinical practice (constituted by representatives of nine societies and by invited experts). International journal of behavioral medicine 19:403-488. doi:https://doi.org/10.1007/ s12529-012-9242-5, European Guidelines on Cardiovascular Disease Prevention in Clinical Practice (Version 2012)

43. Pignone M, Alberts MJ, Colwell JA, Cushman M, Inzucchi SE, Mukherjee D, Rosenson RS, Williams CD, Wilson PW, Kirkman MS (2010) Aspirin for primary prevention of cardiovascular events in people with diabetes: a position statement of the American Diabetes Association, a scientific statement of the American Heart Association, and an expert consensus document of the American College of Cardiology Foundation. Diabetes Care 33:1395-1402. https://doi.org/10.2337/dc10-0555

44. Powner DJ, Hartwell EA, Hoots WK (2005) Counteracting the effects of anticoagulants and antiplatelet agents during neurosurgical emergencies. Neurosurgery 57:823-831; discussion 823-831. https://doi.org/10.1227/01.neu.0000179915.74429.b2

45. Rachinger JC, Koman G, Scheller C, Prell J, Rampp S, Strauss C (2011) Practice in the perioperative prevention of deep vein thrombosis in german neurosurgical departments: is there a trend towards homogenization? Cent Eur Neurosurg 72:115-119. https://doi.org/ 10.1055/s-0031-1280791

46. Schomig A, Neumann FJ, Kastrati A, Schuhlen H, Blasini R, Hadamitzky M, Walter H, Zitzmann-Roth EM, Richardt G, Alt E, Schmitt C, Ulm K (1996) A randomized comparison of antiplatelet and anticoagulant therapy after the placement of coronary-artery stents. N Engl J Med 334:1084-1089. https://doi.org/10.1056/ nejm199604253341702

47. Soleman J, Kamenova M, Guzman R, Mariani L (2017) The Management of Patients with chronic subdural hematoma treated with low-dose acetylsalicylic acid: an international survey of practice. World neurosurgery 107:778-788. https://doi.org/10. 1016/j.wneu.2017.08.065

48. Steinhubl SR, Berger PB, Mann JT 3rd, Fry ET, DeLago A, Wilmer C, Topol EJ (2002) Early and sustained dual oral antiplatelet therapy following percutaneous coronary intervention: a randomized controlled trial. Jama 288:2411-2420. https://doi.org/10.1001/ jama.288.19.2411

49. Sumiyoshi K, Hayakawa T, Yatsushige H, Shigeta K, Momose T, Enomoto M, Sato S, Takasato Y (2017) Outcome of traumatic brain injury in patients on antiplatelet agents: a retrospective 20-year observational study in a single neurosurgery unit. Brain Inj 31: 1445-1454. https://doi.org/10.1080/02699052.2017.1377349

50. Toyoda K, Yasaka M, Iwade K, Nagata K, Koretsune Y, Sakamoto T, Uchiyama S, Gotoh J, Nagao T, Yamamoto M, Takahashi JC, Minematsu K (2008) Dual antithrombotic therapy increases severe bleeding events in patients with stroke and cardiovascular disease: a prospective, multicenter, observational study. Stroke 39:17401745. https://doi.org/10.1161/strokeaha.107.504993

51. Wiebers DO, Whisnant JP, Huston J 3rd, Meissner I, Brown RD Jr, Piepgras DG, Forbes GS, Thielen K, Nichols D, O'Fallon WM, Peacock J, Jaeger L, Kassell NF, Kongable-Beckman GL, Torner JC (2003) Unruptured intracranial aneurysms: natural history, clinical outcome, and risks of surgical and endovascular treatment. Lancet (London, England) 362:103-110. https://doi.org/10.1016/ s0140-6736(03)13860-3

52. Wolff T, Miller T, Ko S (2009) Aspirin for the primary prevention of cardiovascular events: an update of the evidence for the U.S. preventive services task force. Ann Intern Med 150:405-410. https://doi.org/10.7326/0003-4819-150-6-200903170-00009

53. Zacharia BE, Bruce SS, Carpenter AM, Hickman ZL, Vaughan KA, Richards C, Gold WE, Lu J, Appelboom G, Solomon RA, Connolly ES (2014) Variability in outcome after elective cerebral aneurysm repair in high-volume academic medical centers. Stroke 45:1447-1452. https://doi.org/10.1161/strokeaha.113.004412

Publisher's note Springer Nature remains neutral with regard to jurisdictional claims in published maps and institutional affiliations. 